\title{
ANALISIS KESALAHAN BUKU TEKS MATEMATIKA KELAS XI SMA/MA KURIKULUM 2013
}

\author{
Aprilia Dwi Mayangsari $^{1 *}$, P M Labulan², Rusdiana ${ }^{3}$ \\ ${ }^{1,2,3}$ Program Studi Pendidikan Matematika, FKIP Universitas Mulawarman \\ Jalan Muara Pahu, Gn. Kelua, Kec. Samarinda Ulu, Kota Samarinda, Kalimantan Timur, Indonesia \\ e-mail: ${ }^{1}$ apriliadwimayangsari66@gmail.com; ${ }^{2}$ pm_labulan@yahoo.co.id; ${ }^{3}$ ana_diana183@yahoo.com; \\ Submitted: September 25, $2021 \quad$ Revised: October 8, $2021 \quad$ Accepted: October 29, 2021 \\ corresponding author*
}

\begin{abstract}
Abstrak
Buku teks menjadi kebutuhan utama dalam proses pembelajaran yang mengakibatkan beragamnya buku teks dari berbagai penerbit buku. Meskipun Badan Standar Nasional Pendidikan (BSNP) telah menilai kesesuaian buku teks, namun tidak menutup kemungkinan terjadi kesalahan. Sehingga, dengan adanya penelitian ini dapat diketahui jenis-jenis kesalahan dalam buku teks matematika kelas XI SMA/MA Kurikulum 2013. Jenis kesalahan yang dimaksud adalah jenis kesalahan berdasarkan objek matematika yang diantaranya kesalahan fakta, konsep, prinsip, dan operasi. Penelitian ini menggunakan metode penelitian kualitatif dengan pendekatan deskriptif. Teknik analisis data dari penelitian ini adalah teknik Miles dan Huberman. Teknik pengumpulan data dari penelitian ini adalah analisis konten. Hasil dari penelitian ini adalah 8 kesalahan terkait fakta, 12 kesalahan terkait konsep, 12 kesalahan terkait prinsip dan 18 kesalahan terkait operasi. Hasil penelitian ini dapat dijadikan sebagai referensi dalam memilih buku teks matematika yang baik dan tepat.
\end{abstract}

Kata Kunci: analisis kesalahan, buku teks matematika, kurikulum 2013, objek matematika

\section{THE ERROR ANALYSIS OF MATHEMATICS TEXTBOOKS FOR ELEVENTH GRADE SMA/MA CURRICULUM 2013}

\begin{abstract}
Textbooks are a main necessity in learning process which result in variety of textbooks from book publisher. Although the National Education Standards Agency (BSNP) has evaluated textbooks for viability, faults are still possible. Subsequently, the goal of this review is to decide the sorts of blunders identified in mathematics textbooks for the SMA/MA Curriculum 2013 in eleventh grade. There are four sorts of errors based on mathematical objects: factual, conceptual, principle, and operational errors. The qualitative method was combined with a descriptive approach in this study. Miles and Huberman's data analysis technique was applied. Content analysis was employed as a data collection strategy. According to the findings, there are 8 errors related to facts, 12 errors related to concepts, 12 errors related to principles, and 18 errors related to operations. So, the discoveries of this review can be used as an aide while choosing a decent and significant mathematics textbook.
\end{abstract}

Keywords: the error analysis, mathematics textbooks, curriculum 2013, mathematical objects

\section{Pendahuluan}

Pemerintah Indonesia telah mengeluarkan Peraturan Pemerintah Nomor 13 tahun 2015, yang isinya terkait dengan standar nasional buku teks. Buku teks harus dapat membantu siswa dalam menguasai kompetensi sesuai dengan jenjang kelasnya (Ramda, 2017). Buku teks yang digunakan dalam pembelajaran harus jelas, baik yang berkaitan dengan informasi maupun pengetahuan (Kinanti \& Sudirman, 2017). Guru perlu mengetahui dan memperhatikan dengan seksama sumber belajar yang digunakan berupa buku siswa dan buku pegangan guru (Fajriatin, 2015). Hal ini dimaksudkan jika terdapat ketidaksesuaian, kekurangan atau ketidaktepatan dalam buku tersebut, dapat diambil langkah awal untuk menindaklanjuti permasalahan tersebut (Rizkianto \& Santosa, 2017). Senada dengan pendapat Agustina et al. (2020) bahwa kelayakan buku ajar mempengaruhi keberhasilan proses 
pembelajaran di sekolah agar mencapai hasil yang optimal.

Pentingnya buku teks pelajaran sebagai bahan utama penunjang pembelajaran mengakibatkan sangat beragamnya jenis buku teks yang beredar dari berbagai penerbit buku teks. Meskipun buku teks tersebut telah dinilai kesesuaiannya oleh BSNP, namun tidak menutup kemungkinan terjadi kesalahan. Jika terjadi kesalahan pada suatu objek matematika, maka akan menghalangi siswa untuk memahaminya (D. P. Sari, 2016). Hal ini senada dengan pendapat Yurniwati (2015) bahwa hasil belajar siswa tidak sesuai dengan harapan, apabila pendidik menggunakan buku yang kurang tepat. Objek langsung matematika menurut Suyono \& Soemoenar (2014) terdiri dari fakta, konsep, prinsip, dan operasi matematika. Fakta merupakan objek terkait perjanjian dalam matematika seperti simbol, aturan, dan lain sebagainya (Valentino, 2017). Konsep merupakan ide abstrak untuk mengklasifikasikan objek-objek. (Abdussakir, 2017). Prinsip adalah dua atau lebih konsep atau fakta dengan konsep yang saling berhubungan (Andar \& Ikman, 2016). Operasi adalah proses yang dilakukan untuk menemukan solusi tertentu (Setyowati, 2018).

Berdasarkan observasi awal yang peneliti telah lakukan terhadap beberapa guru matematika kelas XI diperoleh informasi bahwa dalam proses pembelajaran matematika, siswa memiliki pemahaman yang berbeda-beda. Sering kali siswa mengeluh kesulitan belajar matematika apabila hanya dengan melihat buku teks saja, siswa membutuhkan penjelasan secara lisan agar siswa paham dengan isi materi dalam buku teks yang digunakan. Selanjutnya, penelitian oleh Diana Purwita Sari (2016), penelitian oleh Erik Valentino (2017) dan penelitian oleh Arroida \& Retnawati (2018) menunjukkan bahwa buku teks matematika yang diteliti masih terdapat beberapa koreksi terkait dengan objek matematika. Hal ini mengindikasikan bahwa meskipun buku teks telah dinilai baik, namun masih memungkinkan adanya kekurangan dalam buku teks tersebut. Penelitian tersebut juga telah mengungkapkan kesalahan penyajian objek matematika beserta alternatif perbaikannya, namun belum menggunakan buku teks matematika dari penerbit yang berbeda sebagai sumber data yang dianalisis. Hal ini dimaksudkan agar guru dan siswa dapat mengetahui jenis kesalahan yang terdapat pada buku teks matematika dari penerbit yang berbeda, sehingga dapat memilih buku pelajaran matematika yang tepat sebagai bahan pendamping belajar.
Berdasarkan paparan di atas, studi ini membahas analisis kesalahan pada buku teks matematika yang memuat indikator-indikator kesalahan dalam mengkategorikan setiap jenis kesalahan objek langsung matematika dan memberikan alternatif perbaikan jawabannya. Selain itu, peneliti mengkaji buku teks matematika dari tiga penerbit buku yang berbeda, sehingga guru dan siswa dapat menjadikan penelitian ini sebagai referensi dalam memilih buku teks matematika. Oleh sebab itu, peneliti tertarik mengangkat judul penelitian "Analisis Kesalahan Buku Teks Matematika Kelas XI SMA/MA Kurikulum 2013”. Dengan demikian, dapat dirumuskan masalah yaitu jenis kesalahan apa yang terdapat pada buku pelajaran matematika kelas XI SMA/MA Kurikulum 2013.

\section{Metode Penelitian}

Tujuan dilakukannya studi ini, untuk mengetahui jenis kesalahan pada buku pelajaran matematika Kelas XI SMA/MA Kurikulum 2013. Metode penelitian kualitatif dengan pendekatan deskriptif dan teknik analisis data Miles dan Huberman digunakan dalam studi ini. Teknik analisis data ini terdiri dari tiga langkah, yaitu reduksi data, display data, dan konklusi (Putri \& Gazali, 2021).

Tahap reduksi data yaitu melakukan pemilihan, pemfokusan, dan penyederhanaan data mentah dalam catatan-catatan tertulis. Tahap display data adalah mendeskripsikan data dalam bentuk teks dan gambar untuk memberikan pemahaman tentang data tersebut. Setelah reduksi data dan display data selesai, dapat dilakukan pengambilan kesimpulan (M. Sari \& Asmendri, 2020).

Analisis konten menjadi teknik pengumpulan data pada penelitian ini. Pemilihan buku yang dianalisis berdasarkan penggunaan buku beberapa sekolah pilihan peneliti di Samarinda. Sekolah-sekolah tersebut merupakan sekolah yang memenuhi kriteria sekolah favorit atau sekolah unggul.

Proses penelitian dari penelitian ini adalah dengan membaca dan menganalisis buku sebagai sumber data untuk dibandingkan dengan buku acuan yang lebih akurat, yaitu buku Kalkulus edisi 9 oleh Varberg, Purcell dan Rigdon, dan buku Kalkulus oleh Drs. Koko Martono, M.Si serta sumber lainnya. Kemudian, sumber data tersebut dapat diketahui apakah terdapat kesalahan penyajian objek matematika. Selanjutnya, hasil analisis terhadap sumber data dikelompokkan berdasarkan indikator jenis kesalahan penyajian objek matematika. Indikator jenis kesalahan 
penyajian objek matematika ditunjukkan dalam tabel 1.

Tabel 1. Indikator Kesalahan Berdasarkan Objek Matematika

\begin{tabular}{|c|c|c|}
\hline Nomor & Tipe kesalahan & Indikator kesalahan \\
\hline \multirow{5}{*}{1.} & \multirow{5}{*}{ Fakta } & 1.1 Kesalahan dalam penggunaan simbol atau notasi matematika \\
\hline & & 1.2 Kesalahan dalam menggunakan istilah matematika \\
\hline & & 1.3 Ketidaklengkapan penulisan simbol atau notasi matematika \\
\hline & & 2.1 Ketidaktepatan dalam menginterpretasikan konsep \\
\hline & & 2.2 Ketidaktepatan dalam penerapan ilustrasi untuk menjelaskan \\
\hline \multirow[t]{3}{*}{2.} & \multirow[t]{3}{*}{ Konsep } & konsep \\
\hline & & 2.3 Pemberian contoh yang kurang sesuai dengan konsep \\
\hline & & $\begin{array}{l}\text { 2.4 Ketidaklengkapan pemberian syarat atau semesta pembicaraan } \\
\text { pada suatu definisi }\end{array}$ \\
\hline \multirow[t]{2}{*}{3.} & \multirow[t]{2}{*}{ Prinsip } & $\begin{array}{l}\text { 3.1 Kesalahan dalam menghubungkan dua atau lebih konsep atau } \\
\text { fakta dengan konsep }\end{array}$ \\
\hline & & 4.1 Kesalahan pada proses perhitungan \\
\hline \multirow[t]{2}{*}{4.} & \multirow[t]{2}{*}{ Operasi } & 4.2 Kesalahan dalam proses pengerjaan \\
\hline & & $\begin{array}{l}\text { 4.3 Informasi alur kerja tidak sesuai dengan informasi yang } \\
\text { diberikan pada awal pertanyaan }\end{array}$ \\
\hline
\end{tabular}

\section{Hasil dan Pembahasan}

\subsection{Deskripsi Buku Teks Matematika}

Sumber data yang digunakan adalah buku pelajaran matematika Kelas XI SMA/MA oleh penerbit Erlangga, Kemendikbud dan YramaWidya Kurikulum 2013. Materi yang diteliti adalah materi Kalkulus yang terdiri dari Limit Fungsi Aljabar, Turunan Fungsi Aljabar dan Integral Fungsi Aljabar.

Berikut deskripsi buku teks matematika yang diteliti pada penelitian ini:

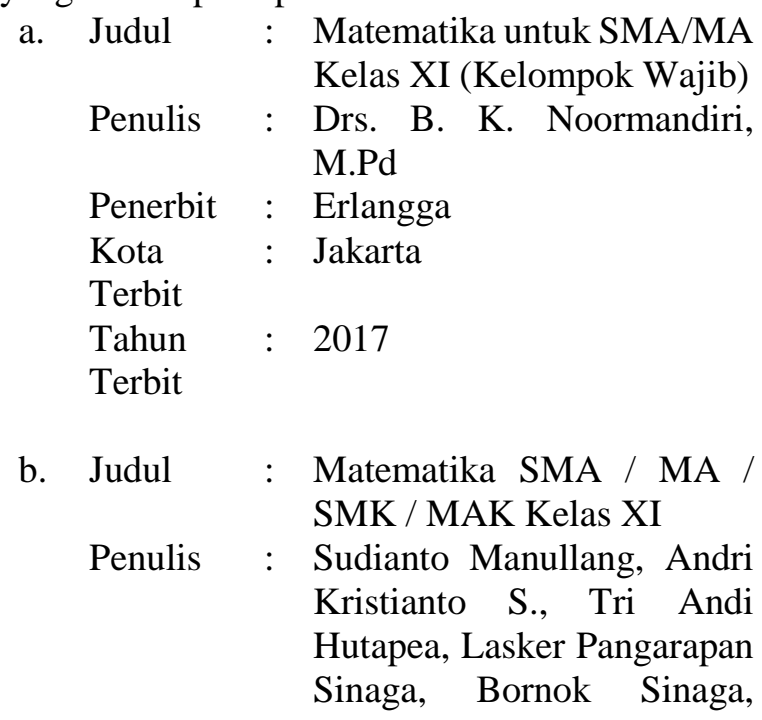

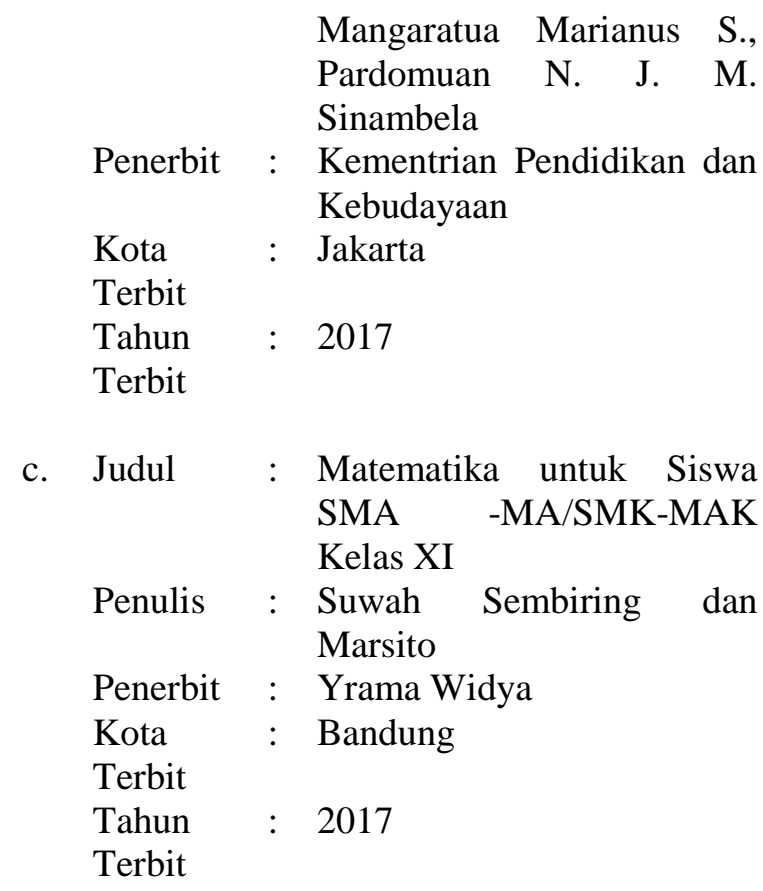

\subsection{Deskripsi Hasil Penelitian}

Berdasarkan hasil analisis terhadap sumber data, ditemukan kesalahan pada buku pelajaran matematika. Hasil penelitian ini disajikan dalam gambar 1. 


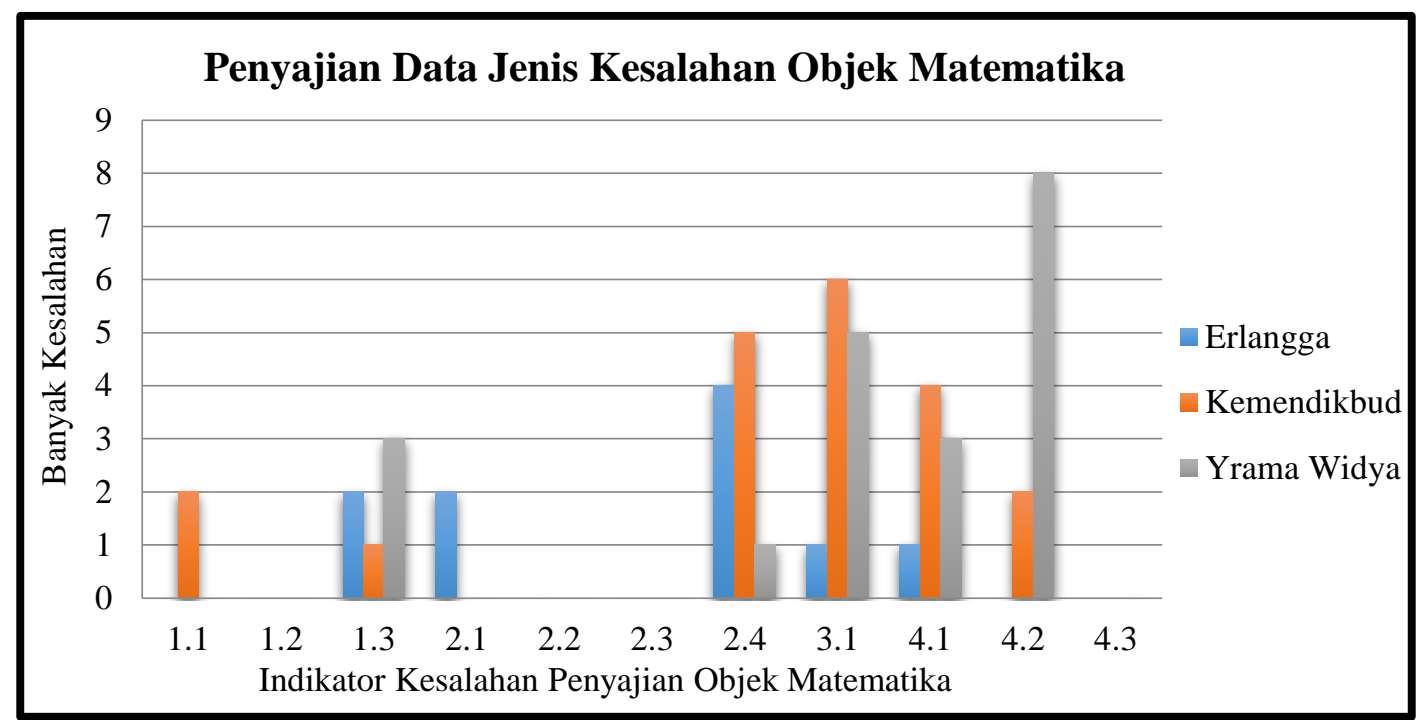

Gambar 1. Penyajian data jenis kesalahan objek matematika

a. Kesalahan penyajian terkait fakta

Pada jenis kesalahan penyajian terkait fakta, terdapat tiga indikator kesalahan fakta dalam penelitian ini. Salah satu indikator kesalahannya adalah kesalahan dalam penggunaan simbol. Hal ini sejalan dengan pendapat Valentino (2017) bahwa objek terkait fakta adalah objek terkait pada perjanjian dalam matematika seperti simbol, aturan dan lain sebagainya. Dalam penelitiannya juga mengkategorikan ketidaksesuaian penggunaan simbol sebagai indikator dari kesalahan fakta. Berikut kesalahan dalam penulisan simbol matematika.

Secara notasi matematika dituliskan $m=\frac{d y}{d x}=f(x)$ sehing $y=f(x)$

$y=f(x)+c)$ Hal ini berarti bahwa nilai konstanta $c$ dapat berubah-ubah.
disenti turunan dari $m$. Dengan demikian anti turunan dari $m$ adal

Jadil, integral adalah antiturunan dari sebuah fungsi.

Gambar 2. Kesalahan fakta pada buku Matematika Kemendikbud halaman 297

Pada gambar 2, terdapat kesalahan dalam penggunaan simbol. Kesalahan ini dinamakan kesalahan fakta yang tidak beraturan dikarenakan dalam penyajiannya memuat beberapa fakta lainnya. Secara umum, $f^{\prime}(x)$ merupakan notasi dari turunan pertama pada fungsi $f(x)$ (Martono, 1999). Pada pembahasan dalam bab 8 Integral Fungsi tersebut, belum terdapat penggunaan simbol $f^{\prime}(x)$ yang menyatakan sebagai turunan pertama. Apabila $m=\frac{d y}{d x}=f(x), \quad$ maka $\quad y=F(x)+C$ merupakan anti turunan dari $\mathrm{m}$ (Varberg et al., 2007). Penulisan yang tepat adalah "Secara notasi matematika dituliskan $m=\frac{d y}{d x}=f(x)$ sehingga $y=F(x)+C$ disebut anti turunan dari $\mathrm{m}$. Dengan demikian anti turunan dari $\mathrm{m}$ adalah $y=F(x)+C$. Hal ini berarti bahwa nilai konstanta $C$ dapat berubah-ubah."

b. Kesalahan penyajian terkait konsep

Pada jenis kesalahan penyajian terkait konsep, peneliti telah menjabarkan empat indikator kesalahan konsep. Salah satu indikator kesalahannya adalah ketidaklengkapan pemberian syarat. Hal ini sejalan dengan pendapat Sari (2016) yang mengkategorikan ketidaklengkapan pemberian syarat sebagai salah satu indikator kesalahan konsep. Selanjutnya, diperjelas oleh pendapat Abdussakir (2017) bahwa objek yang berhubungan dengan konsep adalah ide abstrak untuk mengklasifikasikan objek-objek. Dengan demikian, syarat sangat penting dalam mengklasifikasikan atau mengkategorikan sekumpulan objek. Berikut ketidaklengkapan dalam pemberian syarat.

$$
\begin{aligned}
& \text { Definisi: } \\
& \text { Turunan dari fungsi } f \text { adalah } f^{\prime} \text { sedemikian sehingga nilai fungsi } \\
& \text { ini untuk setiap } x \text { dalam daerah definisi } f \text { dirumuskan sebagai: } \\
& \qquad f^{\prime}(x)=\lim _{h \rightarrow 0} \frac{f(x+h)-f(x)}{h}
\end{aligned}
$$

Gambar 3. Kesalahan konsep pada buku Matematika Erlangga halaman 291

Pada gambar 3 terdapat ketidaklengkapan pemberian syarat. Syarat yang dimaksud adalah syarat dalam menyatakan suatu fungsi turunan pertama. Jika turunan suatu fungsi ada, maka limit yang mendefinisikan turunannya pasti ada, dan fungsinya pasti kontinu. Namun, fungsi yang kontinu, belum tentu memiliki turunan. Turunan fungsi di titik $c$ didefinisikan sebagai 
kemiringan garis singgung suatu fungsi di titik c. Kemiringan garis singgung suatu fungsi di titik c merupakan nilai $\tan \alpha$ yang dilimitkan untuk komponen $x$ mendekati nol. Apabila komponen $x$ bernilai nol, maka tidak akan ada gradien garis singgung. Selanjutnya, fungsi kontinu pasti memiliki limit fungsi, namun limit yang membandingkan komponen $y$ dengan komponen $x$ belum tentu dapat ditemukan. Sebagai contoh fungsi $y=|x-1|$. Fungsi tersebut merupakan fungsi yang kontinu, dan pasti memiliki limit fungsi, namun limit yang membandingkan komponen $y$ dengan komponen $x$ tidak akan ditemukan. Hal ini dikarenakan limit yang mendefinisikan turunan adalah suatu perbandingan antara komponen $y$ dengan komponen $x$. Itu sebabnya dapat terjadi tidak ada nilai limitnya. Hal ini diperlukan penegasan bahwa suatu fungsi kontinu memiliki turunan hanya jika limit yang mendefinisikan turunannya ada. Apabila limit yang mendefinisikan turunan bernilai $\infty$ atau $\infty$, maka dapat dikatakan tidak memiliki turunan (Varberg et al., 2007). Penulisan definisi fungsi turunan pertama yang tepat adalah

"Turunan dari fungsi $f$ adalah $f$ ' sedemikian sehingga nilai fungsi ini untuk setiap $x$ dalam daerah definisi $f$ dirumuskan sebagai:

$$
f^{\prime}(x)=\lim _{h \rightarrow 0} \frac{f(x+h)-f(x)}{h}
$$

Asal ada limitnya dan bukan $\infty$ atau $-\infty$."

c. Kesalahan penyajian terkait prinsip.

Pada jenis kesalahan penyajian terkait prinsip, terdapat satu indikator kesalahan prinsip. Indikator kesalahannya adalah kesalahan dalam menghubungkan dua atau lebih konsep atau fakta dengan konsep. Sejalan dengan pengertian prinsip menurut Andar \& Ikman (2016) adalah hubungan antara dua atau lebih konsep atau fakta dengan konsep. Berikut kesalahan penyajian terkait prinsip.

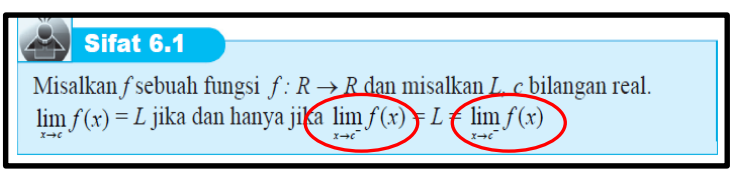

Gambar 4. Kesalahan prinsip pada buku Matematika Kemendikbud halaman 229

Pada gambar 4 terdapat kesalahan dalam menghubungkan konsep dengan fakta. Pada sifat tersebut menunjukkan bahwa limit dikatakan ada, apabila limit kiri dan limit kirinya sama. Padahal limit dikatakan ada, apabila limit kiri dan limit kanannya sama (Varberg et al., 2007). Dengan demikian, pernyataan tersebut tidak dapat menghubungkan konsep limit dengan fakta yang ada. Penulisan yang tepat adalah "Misalkan $f$ sebuah fungsi $f: R \rightarrow R$ dan misalkan L, c bilangan real. $\operatorname{Lim}_{\mathrm{x} \rightarrow c} f(x)=L$ jika dan hanya jika $\lim _{x \rightarrow c^{-}} f(x)=L=\lim _{x \rightarrow c^{+}} f(x)$."

d. Kesalahan penyajian terkait operasi

Pada jenis kesalahan penyajian terkait operasi, terdapat tiga indikator kesalahan operasi dalam penelitian ini. Salah satu indikator kesalahannya adalah kesalahan proses perhitungan. Hal ini sependapat dengan Sari (2016) bahwa objek yang terkait dengan operasi adalah proses memperoleh solusi. Selanjutnya diperjelas oleh pendapat Setyowati (2018) bahwa proses untuk mencari solusi spesifik. Berikut kesalahan pada proses perhitungan.

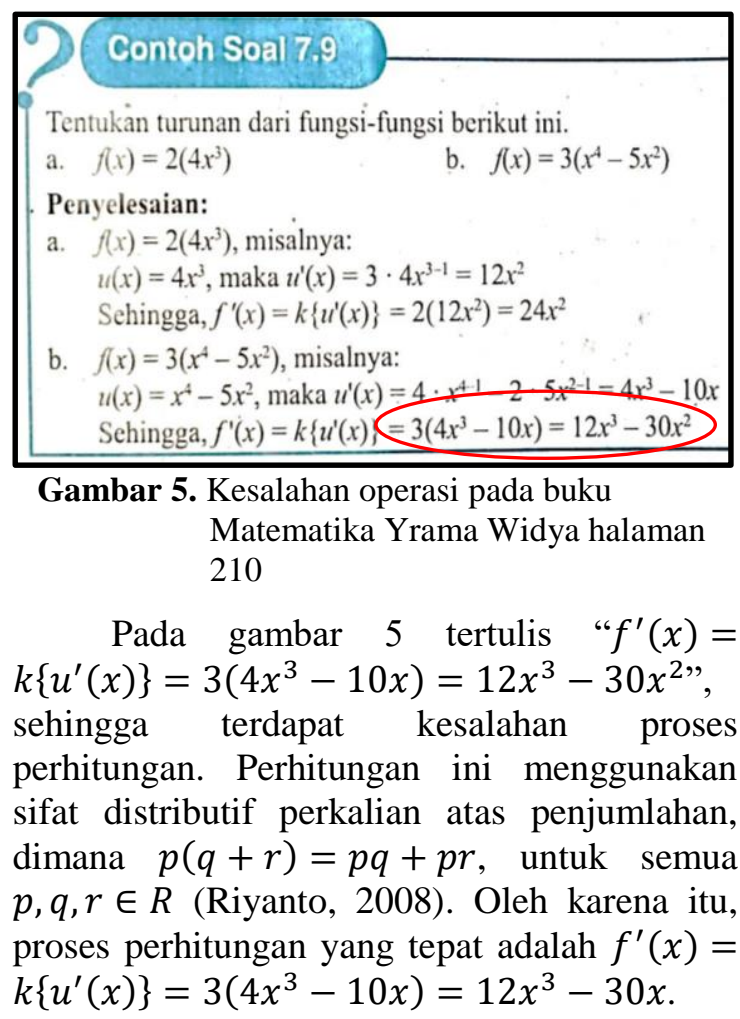

\section{Kesimpulan}

Penyajian objek matematika pada ketiga buku teks matematika kelas XI Kurikulum 2013 ditemukan kesalahan-kesalahan, diantaranya: 8 kesalahan terkait fakta, 12 kesalahan terkait konsep, 12 kesalahan terkait prinsip dan 18 kesalahan terkait operasi. Berikut rincian kesalahan penyajian objek matematika di setiap buku teks matematika.

Pada buku pelajaran matematika kelas XI dengan penerbit buku Erlangga, terdapat 10 
kesalahan yang terdiri dari 2 kesalahan terkait fakta, 6 kesalahan terkait konsep, 1 kesalahan terkait prinsip dan 1 kesalahan terkait operasi.

Pada buku pelajaran matematika kelas XI dengan penerbit Kemendikbud, terdapat 20 kesalahan yang terdiri dari 3 kesalahan terkait fakta, 5 kesalahan terkait konsep, 6 kesalahan terkait prinsip dan 6 kesalahan terkait operasi.

Pada buku pelajaran matematika kelas XI dengan penerbit Yrama Widya, terdapat 20 kesalahan yang terdiri dari 3 kesalahan terkait fakta, 1 kesalahan terkait konsep, 5 kesalahan terkait prinsip dan 11 kesalahan terkait operasi.

Disarankan guru harus mengkaji bagaimana objek matematika yang disajikan dalam buku teks matematika sebelum menggunakannya dalam proses pembelajaran. Peserta didik hendaknya tidak hanya menggunakan satu buku teks saja. Penelitian ini diharapkan dapat menjadi bahan bagi penerbit buku untuk berbenah agar dapat mengurangi kesalahan di kemudian hari.

\section{Daftar Pustaka}

Abdussakir. (2017). Internalisasi Nilai-Nilai Islami dalam Pembelajaran Matematika dengan Strategi Analogi. Seminar Nasional Integrasi Matematika Dan Nilai Islami, 1(1), 1-15.

Agustina, L., Nurhidayah, D., \& Wiratomo, Yogi. (2020). Analisis Materi dan Penyajian pada Buku Teks Matematika SMP / MTs untuk Kelas VIII. Prosiding Seminar Nasional Dan Diskusi Panel Pendidikan Matematika Universitas Indraprasta PGRI, 80, 359-370.

Andar, A., \& Ikman, I. (2016). Deskripsi Kesalahan Siswa dalam Menyelesaikan Soal-Soal Ujian Semester Matematika Siswa Kelas VIII SMP Negeri 10 Kendari. Jurnal Penelitian Pendidikan Matematika, 4(2), 15-28.

Arroida, Azzanie K., \& Retnawati, E. (2018). Analisis Buku Teks Pelajaran Matematika Wajib Kelas X SMA. Jurnal Pendidikan Matematika, 7(3), 2335.

Fajriatin, Alfin. (2015). Analisis Buku Siswa Matematika Kurikulum 2013 Kelas IX Bab Sistem Persamaan Linear Dua Variabel Berdasarkan Konten Pada Kriteria Bell. Makalah Yang Disajikan Di Seminar Nasional Matematika Dan Pendidikan Matematika UNY, ISBN. 978-02-73403-0-5, 71-76.

Kinanti, Lutfia P., \& Sudirman, S. (2017). Analisis Kelayakan Isi Materi Dari Komponen Materi Pendukung Pembelajaran Dalam Buku Teks Mata Pelajaran Sosiologi Kelas Xi Sma Negeri Di Kota Bandung. Sosietas, 7(1), 341-345.

Martono, K. (1999). Kalkulus (D. Subagdja (Ed.); 1st ed.). Erlangga.
Peraturan Pemerintah Republik Indonesia Nomor 13 Tahun 2015 Tentang Perubahan Kedua Atas Peraturan Pemerintah Nomor 19 Tahun 2005 Tentang Standar Nasional. (n.d.).

Putri, Vini W., \& Gazali, Fauzana. (2021). Studi Literatur Model Pembelajaran POGIL untuk Meningkatkan Hasil Belajar Peserta Didik pada Pembelajaran Kimia. Journal of Multidicsiplinary Research and Development, 3(2), 3.

Ramda, Apolonia H. (2017). Analisis kesesuaian materi buku teks Kemendikbud matematika kelas VII dengan Kurikulum 2013. PYTHAGORAS: Jurnal Pendidikan Matematika, 12(1), 13.

Riyanto, M. Z. (2008). Pengantar Analisis Real I.

Rizkianto, I., \& Santosa, Rusgianto H. (2017). The Anaysis Of Junior High School Students Mathematics Book 2013 Curriculum. Mosharafa, 6(2), 230.

Sari, Diana P. (2016). Analisis Kesalahan Buku Teks Matematika SMP/MTS Kelas VII Berdasarkan Objek Kajian Matematika. Prosiding Seminar Matematika Dan Pendidikan Matematika, 77-87.

Sari, Milya, \& Asmendri. (2020). Penelitian Kepustakaan (Library Research) dalam Penelitian Pendidikan IPA. Natural Science:Jurnal Penelitian Bidang IPA Dan Pendidikan IPA, 6(1), 48.

Setyowati, T. (2018). Analisis Kesalaan Prinsip dan Operasi Dalam Menentukan Koordinat Kutub Siswa Kelas X TKJ SMK Muhammadiyah 5 Karanganyar Tahun Pelajaran 2015/2016. Prosiding Seminar Nasional Matematika Dan Pendidikan Matematika, 1-7.

Suyono, \& Soemoenar. (2014). Objek Pembelajaran Matematika Sekolah (pp. 1-40). Universitas Terbuka.

Valentino, E. (2017). Analisis Kesalahan Konten Matematika pada Buku Siswa Tematik Sekolah Dasar Kelas V Semester I Kurikulum 2013. Suska Journal of Mathematics Education, 3(2), 74-82.

Varberg, D., Purcell, Edwin J., \& Rigdon, Steven E. (2007). Calculus (9th ed.). Prentice Hall.

Yurniwati. (2015). Analisis Buku Teks Matematika Untuk Siswa Sekolah Dasar. Jurnal Ilmiah PGSD, V1l(1), 53-60 